Arq. Bras. Med. Vet. Zootec., v.67, n.5, p.1408-1414, 2015

\title{
Desempenho produtivo e econômica de surubins (Pseudoplatystoma sp.) alimentados com níveis de proteína e estocados em tanque-rede
}

\author{
[Growth performance and economic of Pseudoplatystoma sp fed \\ with protein levels reared in net cages] \\ C.A. Honorato ${ }^{1}$, T.T. Ushizima ${ }^{2}$, F.M. Santamaria ${ }^{2}$, C.I. Flores-Quintana ${ }^{3}$, \\ V.M. Marcondes ${ }^{1}$, C.A. Nascimento ${ }^{1}$ \\ ${ }^{1}$ Centro Universitário da Grande Dourados - Unigran - Dourados, MS \\ ${ }^{2}$ Autônomo - Itaporã, MS \\ ${ }^{3}$ Instituto de Ictiología del Nordeste - Facultad de Ciencias Veterinarias - Universidad \\ Nacional del Nordeste - Corrientes, Argentina
}

\begin{abstract}
RESUMO
O surubim (Pseudoplatystoma sp.) é uma das espécie de peixe mais apreciadas para o consumo. Por ser uma espécie carnívora, exige atenção especial no que tange às suas exigências nutricionais. Até o momento, poucos estudos foram realizados para estabelecê-las na fase de engorda, em especial em sistema de cultivo intensivo. O objetivo do presente estudo foi avaliar os desempenhos zootécnico e econômico de surubins (Pseudoplatystoma sp.) na fase final de crescimento, estocados em tanque-rede e alimentados com dietas com diferentes níveis de proteína. Os peixes, com peso de 356,6 $\pm 40,3 \mathrm{~g}$, foram acondicionados em 12 tanques-rede de $18 \mathrm{~m}^{3}$, nos quais permaneceram por cinco meses até adquirirem o peso comercial para abate. O tratamento experimental foi constituído por três dietas extrusadas comerciais, com os níveis de proteína bruta $(36,38,40 \% \mathrm{~PB})$ sendo substituídos gradativamente por carboidratos. Foram avaliados os parâmetros de crescimento, rendimento de filé, enzimas metabólicas e desempenho econômico. O ganho de peso, o ganho de peso diário, o consumo de dieta, a taxa de eficiência proteica, a sobrevivência e o rendimento de filé não apresentaram diferença significativa. A conversão alimentar foi melhor para os peixes alimentados com a dieta com 38 e $40 \%$ PB. Não foram observadas diferenças significativas para os parâmetros de índice hepatossomático e de enzimas hepáticas. Apesar dos maiores gastos com a ração contendo 38\% PB em comparação à dieta com 36\%PB, esta foi a que apresentou o melhor índice de custo por $\mathrm{kg}$ de peixe produzido. Os melhores índices de crescimento e o menor custo de arraçoamento foram obtidos pelos peixes alimentados com a dieta $38 \% \mathrm{~PB}$, sendo esta, portanto recomendada para o arraçoamento na fase final de surubins em tanque-rede.
\end{abstract}

Palavra-chave: fontes proteicas, nutrição de peixes, peixes carnívoros

\begin{abstract}
The Pseudoplatystoma sp. is one of the most appreciated fish species for consumption. Being a carnivorous species, the painted requires special attention regarding their nutritional requirements. To date, few studies have been conducted to establish them in their stage of fattening especially in intensive cultivation systems. The aim of the present study was to evaluate the growth and economic performance of Pseudoplatystoma sp fed with protein levels reared in net cages. The fish weighing from $356.6 \pm 40.3 \mathrm{~g}$ were packed in twelve net cages in $18 \mathrm{~m}^{3}$ in which they remained for five months until acquiring the commercial weight for slaughter. The experimental treatment was constituted by three commercial extruded diets with different crude protein levels (36, 38, 40\% CP) gradually being replaced with carbohydrate. Growth parameters, metabolic enzymes, fillet yield and economic performance were evaluated. The gain in weight, daily weight gain, diet consumption, protein efficiency rate, survival and fillet yield did not show significant difference. The feed conversion was best for fish fed a diet with 38 and $40 \%$ CP. No significant differences were observed for the hepatossomatic index parameters and liver
\end{abstract}

Recebido em 19 de setembro de 2013

Aceito em 4 de maio de 2015

E-mail: clauciahonorato@yahoo.com.br 
enzymes. There were larger expenditures on rations containing 38\% PB compared to the diet with $36 \%$ $C P$, this presented the best index of cost per $\mathrm{kg}$ of fish produced. The best growth rates and lower cost of feeding were obtained by fish fed with a $38 \% \mathrm{CP}$ diet, which is, therefore, recommended for feeding in the final phase of surubins monitored via net cages.

Keyword: protein sources, fish nutrition, carnivorous fish

\section{INTRODUÇÃO}

O surubim, Pseudoplatystoma sp. é uma das espécies nativas importantes no Brasil (Mayumeoshiro et al., 2012; Liranço et al., 2011; Martino et al., 2005). Os surubins apresentam grande potencial para a aquicultura, pois possuem características zootécnicas, organolépticas e de rendimento de carcaça favoráveis ao atendimento do mercado consumidor. Entretanto, para o real desenvolvimento da cadeia produtiva desses peixes, faz necessário-se buscar protocolos mais eficientes para a produção (Crepaldi, 2006), bem como expandir os conhecimentos acerca das suas necessidades nutricionais, a fim de melhorar a eficiência alimentar (Almeida Filho et al., 2012).

A possibilidade de substituição de uma fração da proteína da dieta, por menor que seja, pode representar, em produção de larga escala, não só um efetivo financeiro, mas também um impacto ambiental significativamente menor (Martino et al., 2002). Como o catabolismo oxidativo das proteínas é nutricional e economicamente pouco eficiente, a ação poupadora da proteína por fontes de energia, como o carboidrato, tem sido reportada (Honorato et al., 2010). Em espécies carnívoras, a utilização e a digestibilidade de carboidratos como fonte de energia são aparentemente limitadas (Almeida Filho et al., 2012), embora alguns estudos apontem a possibilidade de efeito poupador de proteína pelo carboidrato para essa espécie (Teixeira et al., 2013; Lundstedt et al., 2004).

$\mathrm{Na}$ piscicultura intensiva, os gastos com alimentação representam de 50 a $70 \%$ dos custos de produção (Tashibana e Castagnolli, 2003) devido aos elevados níveis de proteína dietética. Apesar do custo elevado das dietas, o desempenho proporcionado ainda é insatisfatório (Almeida Filho et al., 2012). Com isso, a análise da produtividade e dos custos que essa fase representa auxiliará o piscicultor na tomada da decisão em relação à compra de insumos (Barros e Martins, 2012; Marengoni et al., 2008).

O objetivo do presente estudo foi avaliar os desempenhos zootécnico e econômico de surubins (Pseudoplatystoma sp.) na fase final de crescimento, estocados em tanque-rede e alimentados com dietas com diferentes níveis de proteína.

\section{MATERIAL E MÉTODOS}

Este trabalho foi desenvolvido com juvenis de surubim (Pseudoplatystoma sp.) provenientes da Empresa de Pescado Mar \& Terra Ltda., ItaporãMS. Os peixes foram transportados até uma das unidades de criação em Ipezal-MS, propriedade parceira da empresa Mar \& Terra. Eles foram acondicionados em tanques-rede e arraçoados até o peso de $356,6 \pm 40,3 \mathrm{~g}$. Posteriormente, foram distribuídos em nove tanques de $18 \mathrm{~m}^{3}$, com 768 peixes, que lá permaneceram durante cinco meses até adquirirem o peso comercial para abate.

A qualidade da água foi monitorada mensalmente com o multiparâmetro HANNA, modelo HI929828-13, no qual foram aferidos: temperatura, oxigênio dissolvido, potencial hidrogeniônico $(\mathrm{pH})$, condutividade elétrica, salinidade e alcalinidade. A temperatura foi aferida diariamente, antes da alimentação, para se realizarem as estimativas de controle de arraçoamento. Foram utilizadas três dietas extrusadas comerciais com os níveis de proteína bruta $(36,38,40 \% \mathrm{~PB})$ sendo substituídos gradativamente por carboidratos (CHO),

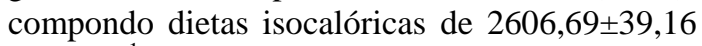
$\mathrm{ED} \mathrm{kcal}^{-1}$ (Tab. 1). As dietas foram adquiridas da empresa Douramix Ltda. (Dourados/MS). As fontes de proteínas utilizadas foram a farinha de peixe e o farelo de soja; o amido gelatinizado foi usado como fonte de carboidrato e o óleo de soja como fonte de lipídeos. As dietas foram suplementados com vitamínico-mineral, vitamina $\mathrm{C}$ protegida, betaína e caulin. 
Tabela 1. Composição bromatológica analisada das dietas com níveis crescentes de proteína digestível para alimentação de surubim

\begin{tabular}{|c|c|c|c|}
\hline \multirow{2}{*}{ Composição (\%) } & \multicolumn{3}{|c|}{ Níveis de proteína bruta (\%) } \\
\hline & 36 & 38 & 40 \\
\hline Matéria seca & 92,3 & 91,85 & 92,85 \\
\hline Proteína bruta & 35,77 & 38,14 & 39,39 \\
\hline Proteína digestível * & 24,99 & 26,21 & 27,44 \\
\hline Lipídeos & 7,72 & 8,75 & 9,72 \\
\hline Extrativo não nitrogenado & 36,97 & 32,19 & 30,48 \\
\hline Fibra bruta & 2,4 & 2,34 & 2,02 \\
\hline Matéria mineral & 9,44 & 10,43 & 11,24 \\
\hline Cálcio & 3,03 & 3,14 & 3,61 \\
\hline Fósforo & 1,71 & 1,81 & 1,88 \\
\hline Energia bruta $\left(\mathrm{kcal} . \mathrm{kg}^{-1}\right)$ & 4343,8 & 4244,5 & 4279,2 \\
\hline Energia digestível $\left(\mathrm{kcal}^{\mathrm{kg}}{ }^{-1}\right)^{*}$ & 2623,86 & 2596,62 & 2557,42 \\
\hline
\end{tabular}

*Proteína e energia digestível calculada com base nos percentuais de digestibilidade dos ingredientes para o surubim (Pseudoplatystoma corruscans) de Gonçalves e Carneiro (2004). Composição analisada das dietas segundo AOAC (2000).

Os parâmetros de desempenho produtivo avaliados foram: ganho de peso $(\mathrm{GP})=$ (peso final - peso inicial); consumo de dieta $(\mathrm{CD})=$ consumo médio de alimento na parcela/ tempo experimental; conversão alimentar $(\mathrm{CA})=$ consumo de alimento / ganho de peso total; taxa de crescimento específico $(\mathrm{TCE})=(\ln$ peso final - In peso inicial) x 100 / tempo; taxa de eficiência proteica $(\mathrm{TEP})=$ ganho de peso vivo / proteína bruta consumida. Ao final do período, foi realizada a contagem de todos os exemplares para o cálculo de sobrevivência.

Dez peixes de cada tratamento foram anestesiados com benzocaína (100mg. $\mathrm{L}^{-1}$ de água) e sacrificados por transecção medular. Os peixes foram filetados, e coletaram-se intestino e fígado (Comitê de Técnicas de Biossegurança e Ética: Processo 104/11). O fígado dos peixes foi retirado e pesado para o cálculo do índice hepatossomático $(\mathrm{IHS})=$ peso do órgão/peso do animal. Os peixes foram filetados para o cálculo do rendimento de filé $(\mathrm{RE})=$ peso do filé/peso do peixe.

Amostras de fígado de 100mg foram homogeneizadas com tampão fosfato de sódio (glicerol v/v em tampão fosfato de sódio $20 \mathrm{mM} \mathrm{e}$ Tris $10 \mathrm{mM}-\mathrm{pH} 7,0)$ em homogeneizador tipo
Potter-Elvehjem. Posteriormente, essas amostras foram centrifugadas a $4^{\circ} \mathrm{C}$ por três minutos a $600 \times g$, e o sobrenadante foi submetido a uma nova centrifugação por oito minutos a $6000 \times \mathrm{g}$. Utilizou-se o sobrenadante para os ensaios enzimáticos da alanina aminotransferase (ALT) e da aspartato aminotransferase (AST). As mensurações da atividade da ALT e da AST foram determinadas por uma modificação do método de Reitman; Frankel (1957). As leituras das amostras foram realizadas por espectrofotometria (espectrofotômetro semiautomático Bioplus S200), com luz de comprimento de onda apropriado para cada teste.

No intuito de serem observados os gastos com ração em reais ( $\mathrm{R}$ \$) e em dólares (US\$) (foi utilizado o valor dólar médio do ano de $2009=$ $\mathrm{R} \$ 1,78$ US\$-1), realizou-se a avaliação do consumo de ração e do valor pago por ela para tanque-rede. Calcularam-se o índice de eficiência econômica (IEE) e o índice de custo médio, propostos por Liranço et al. (2011).

Os resultados de desempenho produtivo foram avaliados em delineamento experimental inteiramente ao acaso (DIC), com três tratamentos e três repetições. Os resultados de 
índice hepatossomático, rendimento de filé e enzimas hepáticas foram analisados em delineamento experimental inteiramente ao acaso (DIC), com três tratamentos e 10 repetições. As análises de variância (ANOVA) e as médias foram comparadas pelo teste de Tukey $(\mathrm{P}<0,05)$, utilizando-se o programa Statistical Analysis System (SAS Intitule Inc., version 6.12, 1999).

\section{RESULTADOS E DISCUSSÃO}

Os resultados de desempenho produtivo dos juvenis de surubins são apresentados na Tab. 2. As médias de ganho de peso, ganho de peso diário, consumo de dieta, taxa de eficiência proteica e sobrevivência não apresentaram diferença significativa. O ganho de peso diário foi semelhante aos observados para a mesma espécie em tanque-rede (Scorvo Filho et al.,
2008). Campos (2003) avaliou como positivos os indicadores de viabilidade socioeconômica e ambiental da criação do surubim criado em tanques-rede no Pantanal do estado do Mato Grosso do Sul. O desempenho do surubim em sistema de tanque-rede foi de 3,59g de ganho de peso diário e com conversão alimentar de 3,11 (Burkert et al., 2008). Apesar de muito relatada a baixa eficiência de aproveitamento de energia para espécies carnívoras (Booth et al., 2013; Almeida Filho et al., 2012), neste estudo com surubins na fase final de crescimento, o desempenho não foi afetado pela diminuição de proteína da dieta. Esses resultados corroboram os observados para juvenis de surubim (170g) cujo aumento dos níveis de proteína de $360-520 \mathrm{~g} / \mathrm{kg}$ nas dietas não aprimorou a utilização de nutrientes (Teixeira et al., 2013)

Tabela 2. Índice de crescimento e rendimento de filé de surubins alimentados com dietas contendo diferentes níveis de proteína

\begin{tabular}{|c|c|c|c|c|c|}
\hline \multirow[b]{2}{*}{ Parâmetros } & \multicolumn{3}{|c|}{ Proteína bruta $(\%)$} & \multirow{2}{*}{$\mathrm{F}$} & \multirow{2}{*}{ C.V. } \\
\hline & 36 & 38 & 40 & & \\
\hline Ganho de peso (g) & 568,66 & 675,57 & 739,79 & $2,45^{\mathrm{NS}}$ & 19,69 \\
\hline Ganho de peso diário (g.dia ${ }^{-1}$ ) & 3,79 & 4,50 & 4,93 & $0,16^{\mathrm{NS}}$ & 1,31 \\
\hline Consumo de dieta $\left(\right.$ g.dia $\left.{ }^{-1}\right)$ & 10,32 & 9,80 & 10,83 & $0,25^{\mathrm{NS}}$ & 21,41 \\
\hline Conversão alimentar & $1,84 \mathrm{~A}$ & $1,34 \mathrm{~B}$ & $1,31 \mathrm{~B}$ & $7,09 *$ & 16,69 \\
\hline Taxa de crescimento específico $\left(\% \cdot\right.$ dia $\left.^{-1}\right)$ & $0,62 \mathrm{~B}$ & $0,71 \mathrm{~A}$ & $0,75 \mathrm{~A}$ & $7,77 *$ & 12,03 \\
\hline Taxa de eficiência proteica $\left(\right.$ g.dia $\left.^{-1}\right)$ & 1,50 & 1,91 & 1,95 & $1,92^{\mathrm{NS}}$ & 19,40 \\
\hline Sobrevivência (\%) & 78,20 & 87,60 & 81,70 & $0,78^{\mathrm{NS}}$ & 13,16 \\
\hline Rendimento de filé $(\%)$ & 54,52 & 56,31 & 54,22 & $2,6^{\mathrm{NS}}$ & 2,20 \\
\hline
\end{tabular}

Coeficiente de variação (C.V.)

Os valores de sobrevivência não apresentaram diferença entre os tratamentos experimentais. Estes variaram entre 78 e $87 \%$, decorrentes do processo de criação comercial, o qual submete os peixes a variações ambientais. Marengoni et al. (2008) descrevem que fatores ambientais e de qualidade de água e de manejo são causas de aumento da taxa de mortalidade do sistema de produção.

A conversão alimentar foi melhor para os peixes alimentados com as dietas com 38 e $40 \%$ PB, sem diferença significativa entre estes. Os valores de conversão alimentar deste estudo foram semelhantes aos obtidos por Teixeira et al. (2013) para juvenis de surubim, cujo valor ótimo de conversão alimentar correspondeu a 38\%PB, e por Kubitza et al. (1998), para a mesma espécie com tamanho entre 600 e $3000 \mathrm{~g}$, com conversão de 2,0:1. Zanardi et al. (2008), para alevinos de Pseudoplatystoma corruscans, observaram conversão alimentar entre 2,37 e 3,94. Scorvo Filho et al. (2008), entretanto, para o sistema em tanque-rede, observaram valores de 4,6 a 5,2 e atribuíram esses índices a fatores como adaptação dos peixes ao tanque-rede devido à maior disputa no momento de capturar o alimento. Essas diferenças nos valores de conversão alimentar do surubim estão relacionadas ao tamanho do peixe (Kubitza et al., 1998) e também ao sistema de produção 
intensivo ou extensivo (Scorvo Filho et al., 2008).

Os peixes alimentados com as dietas com maior nível de proteína apresentaram aumento na taxa de crescimento específico (Tab. 2). Em um estudo com inclusão de fonte de energia para o crescimento de Pseudoplatystoma sp., observouse diminuição do crescimento nos níveis mais elevados (Bicudo et al., 2012). De acordo com Almeida Filho et al. (2012), o surubim apresenta baixa habilidade no aproveitamento de carboidrato. Takahashi e Cyrino (2006), no entanto, não observaram redução dos índices de crescimento com inclusão de $29 \%$ de carboidrato na dieta. Lundstedt et al. (2004) demonstraram que o nível de carboidrato para o surubim está entre 13 e $25 \%$, o que revela a possibilidade de efeito poupador de proteína por inclusão de carboidrato na dieta do surubim. Teixeira et al. (2013) relataram para surubim que níveis crescentes de energia dietética favorecem o ganho de peso e de proteína.
Os rendimentos de filé dos surubins deste estudo não apresentaram diferença significativa entre os tratamentos (Tab. 2), com valores entre 54,22 e $56,31 \%$. Resultados semelhantes foram observados para a mesma espécie por Crepaldi et al. (2008), com rendimento de filé (filé de lombo e filé de barriga) entre 47,95 e 49,16\%, e Burkert et al. (2008), de 47,79\%. O rendimento das partes comestíveis assim como o peso de abate, segundo Barros e Martins (2012), são fatores essenciais para a rentabilidade do sistema de produção.

Não foram observadas diferenças estatísticas para os parâmetros de IHS, ALT e AST (Tab. 3). Esses resultados são positivos, pois demonstram a capacidade dos surubins em metabolizar os níveis de proteína ofertados na dieta. A diminuição da atividade das enzimas de metabolismo proteico em face do aumento de carboidrato das dietas não é observada para espécies carnívoras como Pseupatystoma corrruscans (Lundestedt, 2004) e Salmo solar (Hemre et al., 2007).

Tabela 3. Índice hepatossomático, alanina aminotransferase (ALT) e aspartato aminotransferase (AST) de surubins alimentados com dietas contendo diferentes níveis de proteína

\begin{tabular}{|c|c|c|c|c|c|}
\hline \multirow[b]{2}{*}{ Parâmetros } & \multicolumn{3}{|c|}{ Proteína bruta $(\%)$} & \multirow{2}{*}{$\mathrm{F}$} & \multirow{2}{*}{ C.V } \\
\hline & 36 & 38 & 40 & & \\
\hline Índice hepatossomático & 0,96 & 1,05 & 1,15 & $0,15^{\mathrm{NS}}$ & 17,28 \\
\hline ALT (U.mg proteina ${ }^{-1}$ ) & 1427,3 & 1100,1 & 1326,5 & $1,69^{\mathrm{NS}}$ & 23,38 \\
\hline AST (U.mg proteina ${ }^{-1}$ ) & 641,3 & 606,3 & 550,1 & $1,20^{\mathrm{NS}}$ & 32,51 \\
\hline
\end{tabular}

Coeficiente de variação (C.V.)

O aumento da relação proteína/carboidrato resulta em aumento da atividade da ALT e da AST para Randia quelen (Melo et al., 2006) e em aumento da atividade da ALT para Sparus aurata (Fernandez et al., 2007). Sánchez-Muros et al. (1998) associaram a alta atividade dessas enzimas ao aumento da neoglicogênese. A invariabilidade nas concentrações dessas enzimas neste estudo com surubim é um indicativo que revela que as proteínas da dieta não foram utilizadas como fonte de energia.

A análise econômica dos custos de produção de surubins destinados para o abate, estocados em tanque-rede (Tab. 4), possibilita a tomada de decisão em relação à dieta a ser empregada. Segundo Liranço et al. (2011), a ração é o ponto de maior custo de produção, sendo o que apresenta a maior variação nos custos operacionais. $\mathrm{O}$ aumento de proteína na ração acarreta maior custo desse produto, uma vez que é a fração mais onerosa desse insumo (Tashibana e Castagnolli, 2003).

Ao se avaliarem os custos de gasto de ração para produção de surubim destinada ao abate para comercialização, observou-se que, apesar dos maiores gastos com a ração contendo $38 \% \mathrm{~PB}$ em comparação à dieta com $36 \% \mathrm{~PB}$, ela foi a que apresentou o melhor índice de custo por $\mathrm{kg}$ de peixe produzido (Tab. 4). Barros e Martins (2012), em um estudo de viabilidade de produção de peixes, descrevem que o cultivo em sistema intensivo é economicamente viável, no entanto 
há necessidade de melhora nos índices de desempenho, a qual refletirá nos indicadores econômicos. Alguns autores relatam que o preço pago pela ração é o ponto decisivo na estimativa do custo operacional parcial e na incidência de custo (Marengoni et al., 2008). Portanto, é indispensável para a propriedade aquícola a escolha da dieta com melhor custo-beneficio.

Tabela 4. Consumo de ração, gastos com ração em real e em dólar, produção de peixe e custo do quilo do peixe em real e em dólar, durante o período de crescimento final do surubim criado em tanque-rede

\begin{tabular}{|c|c|c|c|}
\hline \multirow{2}{*}{ Parâmetros } & \multicolumn{3}{|c|}{ Proteína bruta $(\%)$} \\
\hline & 36 & 38 & 40 \\
\hline Consumo de ração $(\mathrm{kg})$ & 928,00 & 924,00 & 896,00 \\
\hline Gastos com ração $(\mathrm{R} \$)$ & 1367,25 & 1401,40 & 1427,63 \\
\hline Gastos com ração (US\$) & 760,96 & 784,48 & 799,16 \\
\hline Gastos com ração /peixe ( $\left.\mathrm{R} \$ . \mathrm{kg}^{-1}\right)$ & 0,74 & 0,72 & 0,83 \\
\hline Produção (kg) & 1050,32 & 1317,36 & 1279,84 \\
\hline Custo $\mathrm{kg}$ peixe $\left(\mathrm{R} \$ . \mathrm{kg}^{-1}\right)$ & 1,30 & 1,06 & 1,12 \\
\hline Custo kg peixe (US\$. $\mathrm{kg}^{-1}$ ) & 0,72 & 0,60 & 0,62 \\
\hline
\end{tabular}

Média da cotação do dólar comercial vendido em reais no período do ensaio de crescimento - US\$ 1,78. http://www.acsp.com.br/indicadores/IEGV/IEGV_DOLAR.HTM.

\section{CONCLUSÃO}

A dieta que proporcionou os melhores índices de crescimento e o menor custo de arraçoamento foi a que continha $38 \%$ de proteína bruta, sendo, portanto, recomendada para o arraçoamento na fase final de surubins em tanque-rede.

\section{AGRADECIMENTO}

À empresa Mar \& Terra, pelo financiamento e pela execução do projeto; à Dra. Fernanda P. L. Zauith, diretora do Hospital Veterinário da Unigran (Fundect 23/200.235/2014 - 087).

\section{REFERÊNCIAS}

ALMEIDA FILHO, R.L.; HONORATO, C.A; DE ALMEIDA, L.C. et al. Nutrição de surubim (Pseudoplatystoma sp.): desafio para aquicultura. Rev. Eletr. Nutritime, v.9, n.5, p.1995-2010, 2012.

ASSOCIATION OF OFFICIAL ANALYTICAL CHEMISTS (A.O.A.C.). 2000. Official Methods of Analysis of AOAC INTERNATIONAL 18. ed., A.O.A.C. INTERNATIONAL.

BARROS, A.F.; MARTINS, M.I.E.G. Performance and economic indicators of a large scale fish farming in Mato Grosso, Brazil. Rev. Bras. Zootec., v.41, p.1325-1331, 2012.

BICUDO, Á.J.D.A.; BORGHESI, R.; DAIRIKI, J.K. et al. Performance of juveniles of Pseudoplatystoma fasciatum fed graded levels of corn gluten meal. Pesqui. Agropecu. Bras., v.47, p.838-845, 2012.
BOOTH, M.A.; MOSES, M. D.; ALLAN, G. L. et al. Utilisation of carbohydrate by yellowtail kingfish Seriola lalandi. Aquaculture, v.376-379, p.151-161, 2013.

BURKERT, D.; ANDRADE, D. R.; SIROL, R. N. et al. Rendimentos do processamento e composição química de filés de surubim cultivado em tanquesrede. Rev. Bras. de Zootec., v.37, p.1137-1143, 2008.

CAMPOS J. L. The culture of pintado, Pseudoplatystoma spp. (Pimelodidae). In: WORLD AQUACULTURE, 2003, Salvador. Proceedings... Salvador: World Aquaculture Society, 2003. p.150. Resumo.

CREPALDI, D. V.; TEIXEIRA, E.A.; FARIA, P. M. et al. Rendimento de carcaça em surubim (Pseudoplatystoma spp.) avaliado por ultra-som. Rev. Bras. Saúde Prod. Anim., v.9, p. 813 - 824, 2008.

FERNANDEZ, F.; MIGUEL, A.G.; CÓRDOBA, M. et al. Effects of diets with distinct protein-tocarbhydrate ratios on nutrient digestibility, growth, body composition and liver intermediary enzymes activities in gilthead sea bream (Sparus aurata L.) fingerlings. J. Exp. Mar. Biol. Ecol., v.343, p.1-10, 2007.

GONÇALVES, E. G.; CARNEIRO, D. J. Coeficientes de digestibilidade aparente da proteína e energia de alguns ingredientes utilizados em dietas para o pintado (Pseudoplatystoma coruscans). Rev. Bras. Zootec., v.32, p.779-786, 2003.

HEMRE, G.I.; SAGSTAD, A.; BAKKE-MCKELLEP, A.M. et al. Nutricional, physiological and histological responses in Atlantic salmo, Salmo salar L. fed diets with genetically modified maize. Aquac. Nutr., v.13, p.186-199, 2007. 
HONORATO, C.A.; ALMEIDA, L.C.; SILVA NUNES, C. et al. Effects of processing on physical characteristics of diets with distinct levels of carbohydrates and lipids: the outcomes on the growth of pacu (Piaractus mesopotamicus). Aquac; Nutr., v.16, p.91-99, 2010

KUBITZA, F.; CAMPOS, J.L.; BRUM, J.A. Produção intensiva no Projeto Pacu Ltda. e Agropeixe Ltda. Pan. Aqüic., v.8, p.41-49. 1998.

LIRANÇO, A.D.S.; ROMAGOSA, E.; SCORVOFILHO, J.D. Desempenho produtivo de Pseudoplatystoma corruscans estocados em sistemas de criação: semi-intensivo (viveiro escavado) e intensivo (tanque-rede). Ciênc. Rural, v.41, p.524-530, 2011.

LUNDSTEDT, L. M.; MELO, J. F. B.; MORAES, G. Digestive enzymes and metabolic profile of Pseudoplatystoma corruscans (Teleostei: Siluriformes) in response to diet composition. Comp. Biochem. Physiol., v.137B, p.331-339, 2004.

MARENGONI, N.G.; BUENO, G.W.; GONÇALVES JÚNIOR, A.C. et al. Desempenho produtivo e viabilidade econômica de juvenis de tilápia-do-Nilo cultivados na região oeste do Paraná sob diferentes densidades de estocagem. Rev. Bras. Saúde Prod. Anim., v.9, p. 341-349, 2008.

MARTINO, R.C., CYRINO, J.E.P., PORTZ, L. et al. Performance, carcass composition and nutrient utilization of surubim Pseudoplatystoma coruscans (Agassiz) fed diets with varying carbohydrate and lipid levels. Aquac. Nutr., v.11, p.131-137, 2005.

MARTINO, R.C.; CYRINO, J.E.P.; PORTZ, L. et al. Performance and fatty acid composition of surubim (Pseudoplatystoma coruscans) fed diets with animal and plant lipids. Aquaculture, v.209, p.233-246, 2002.

MAYUMEOSHIRO, F.; FRAGA, T.L.; HONORATO, C.A. Tempo de trânsito gastrointestinal do pintado (Pseudoplatystoma sp.). J. Agron. Sci., v.1, p.128-138, 2012.

MELO, J.F.B.; LUNDSTEDT, L.M.; METÓN I. et al. Effects of dietary levels of protein on nitrogenous metabolism of Rhamdia quelen (Teleostei: Pimelodidae) Comp. Biochem. Physiol., v.145, Part A, p.181-187, 2006.
REITMAN, S.; FRANKEL, S. A colorimetric method for determination of serum glutamic oxaloacetic and glutamic pyruvic transaminase. Am. J. Clin. Pathol., v.28, 1957.

SÁNCHEZ-MUROS, M.J.; GÁRCIA-REJÓN,L.; GÁRCIA-SALGUERO, L. et al. Long-term nutritional effects on the primary liver and kidney metabolism in raimbow trout. Adaptive response to starvation and high-protein, carbohydrate-free diet on glutamate dehydrogenase and alanine aminotransferase kinetics. Biochem. Cell Biol., v.30. p.55-63, 1998.

SCORVO FILHO, J.D.; ROMAGOSA, E.; AYROZA, L.M. et al. Desempenho produtivo do pintado, Pseudoplatystoma corruscans (spix \& agassiz, 1829), submetidos a diferentes densidades de estocagem em dois sistemas de criação: intensivo e semi-intensivo. Bol. Inst. Pesca, v.34, p.181-188, 2008.

TACHIBANA, L.; CASTAGNOLLI, N. Custo na alimentação dos peixes: é possível reduzir mantendo a qualidade? Pan. Aquic., v.75, p.55-57, 2003.

TAKAHASHI, L.S.; CYRINO, J.E.P. Dietary carbohydrate level on growth performance of speckled catfish, Pseudoplatystoma coruscans. J. Aquac. Trop., v.21, p.13-19, 2006.

TEIXEIRA, E.A.; EULER, A.C.C.; FARIA, P.M.C. et al. Performance and nutrient utilization in South American juvenile catfish Pseudoplatystoma spp. weighting $89-170 \mathrm{~g}$, fed at different energy and protein levels. Arq. Bras. Med. Vet. Zootec., v.65, p.1500-1508, 2013.

USER'S guide: satistic. Versão 6.08, 4 ed. Cary, North Caroline: SAS, 1996. 846 p.

ZANARDI, M.F.; BOQUEMBUZO, J.E.; KOBERSTEIN, T.C.R. Desempenho de juvenis de pintado (Pseudoplatystoma coruscans) alimentados com três diferentes dietas. Rev. Acad. Cienc. Agrar. Amb.., v.6, p.445-450, 2008 